\title{
Research on Farmland Information Collecting and Processing Technology Based on DGPS
}

\author{
Weidong Zhuang and Chun Wang \\ College of Engineering, Heilongjiang Bayi Agriculture University, \\ Daqing, China \\ 81nd@163. com
}

\begin{abstract}
In order to realize the farmland information pinpointing acquisition, this paper has conducted the technology research for farmland information collecting and processing based on the DGPS. According to the precision agriculture's demand which agricultural condition information should be made positional, fast, precise, continuous acquisition, system uses the DGPS receiver and the touch-screen computer, uses Microsoft Access database and uses Visual Basic 6.0 to establish the application program, which used in the farmland information acquisition and processing. According to the farm land contract's demand, the method is established by using DGPS receiver to survey and drawing for field length of side and the area, which was applied in the farm and the effect was good. The result shows that this technology had very good usability.
\end{abstract}

Keywords: DGPS, information collecting and processing, area survey, precision agriculture.

\section{Introduction}

The application of Precision Agriculture can change the traditional agriculture of extensive and managing mode, essences the farmland homework, reduces the production cost, protect the ecological environment, increase economic benefits. GPS (global positioning system) and GIS (geographic information system) is the key technology of precision agriculture, and it is in large quantities of application in agricultural production ${ }^{[1-8]}$. This article is aimed at the need that is the measure of fast farmland. The system uses differential signals of the DGPS receiver, develop application software for receiving and dealing with GPS data, farmland circumference, measuring and calculating the area of land and drawing, in order to improve the efficiency of information acquisition and farmland quality, reduce cost, and easy work.

\section{Receiving and Processing the GPS Data}

\subsection{Receiving the GPS Data}

GPS receiver usually adopts the provisions of NMEA 0183 data output of information, It is should be at least two GPS positioning data that contains GGA and RMC. 
The computer can receive data form GPS receiver by port RS - 232, and will locate data income with MSComm control. The GPS data is analyzed, and some information is got from GPS receiver such as latitude, longitude of the receiving antenna and differential information, satellite number, speed, etc.

\subsection{Limiting Average Filtering}

Limiting average filtering are refer to the recent data which each time the sampling arrives to carry on Limiting processing first, then carries on average filter processing. It is advantage that it can eliminate the accidentally appears pulse interference which can cause sampling value deviation. Because the data obtained from DGPS receivers in the positioning information which includes velocity information, and the speed information can be used for limiting average filtering in the field survey, so as to improve the accuracy of the measurement. A position's information for the field of sampling point, can use speed $\mathrm{v}$ is smaller than setting threshold VT, in $\mathrm{n}$ times average point positioning information as the measured value, Formula is as follows:

$$
Y=\frac{1}{n} \sum_{1}^{n} X_{(i)}, \text { if } \quad v_{i}<V_{T}
$$

\subsection{Projection Transformation}

Because the GPS receiving data is three-dimensional coordinates, but it usually uses the plane rectangular coordinates in the actual survey. Therefore it must be carried on the coordinate transformation. For actual surveys the application, WGS-84 ellipsoidal coordinates, which use latitude and longitude, should be transformed to the plane rectangular coordinate system according to 6 degree or 3 degree belt projections. Now, Gauss-Kruger or UTM projection is often be used, they belong to the horizontal axis of the Mercator projection. When the central meridian coefficient of length $\mathrm{m} 0=1$, it called the Gauss projection. When $\mathrm{m} 0=0.9996$, it called the UTM projection. It should be pointed out that when farmland cross standard project belt, the unique central longitude should be established for the all fields in same projection zone.

\section{Perimeter Area Computation}

\subsection{Farmland Perimeter}

IF we know two points coordinates $\left(x_{1}, y_{1}\right),\left(x_{2}, y_{2}\right)$, The distance of two points $\mathrm{dAB}$ can be computed with the plane distance formula, Formula is as follows:

$$
d_{A B}=\sqrt{\left(x_{2}-x_{1}\right)^{2}+\left(y_{2}-y_{1}\right)^{2}}
$$

Under the situation of every of farmland vertex coordinates $\left(x_{k}, y_{k}\right)$, farmland perimeter $\mathrm{P}$ formulas is as follows: 


$$
\begin{gathered}
P=\sum_{k=1}^{n} \sqrt{\left(x_{k+1}-x_{k}\right)^{2}+\left(y_{k+1}-y_{k}\right)^{2}} \\
\text { Note: } x_{n+1}=x_{1}, \quad y_{n+1}=y_{1}
\end{gathered}
$$

\subsection{Farmland Area}

In consideration of undulating plot, plot is flat polygon farmland, In the case of measuring every farmland vertex coordinates $\left(x_{k}, y_{k}\right)$, Farmland area can be available of plane deformation formula to calculate, formulas is as follows:

$$
\begin{gathered}
S=\frac{1}{2} \sum_{k=1}^{n}\left(x_{k} y_{k+1}-x_{k+1} y_{k}\right) \\
\text { Note: } x_{n+1}=x_{1}, \quad y_{n+1}=y_{1}
\end{gathered}
$$

If the farmland vertex is clockwise arranged, its area $\mathrm{S}$ is negative, When it is arranged for counterclockwise, its area $s$ is positive ${ }^{[9]}$. Therefore, the area can be calculated from absolute $S$, then all the farmland area is positive number.

\section{Programming}

According to the precision agriculture's demand which agricultural condition information should be made positional, fast, precise, continuous acquisition, we develop

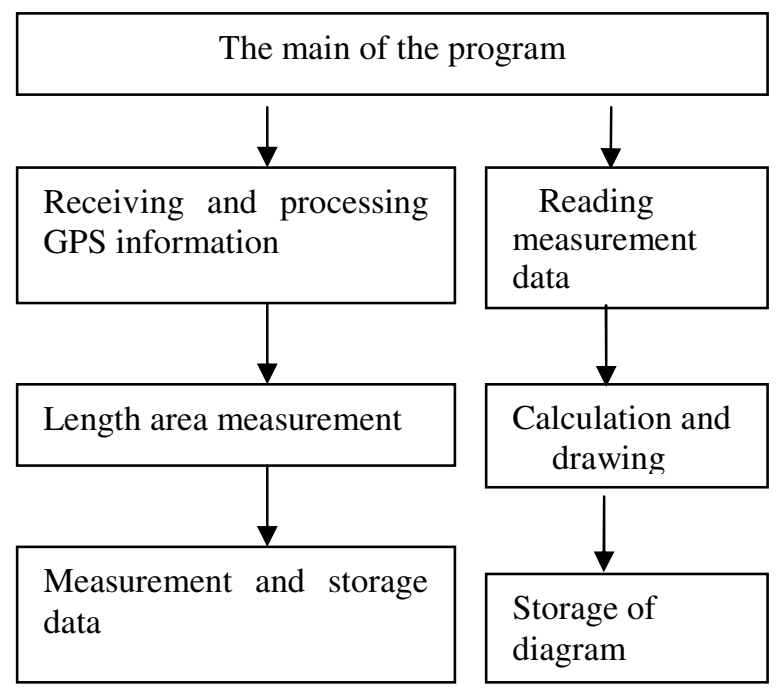

Fig. 1. Structure of software system 


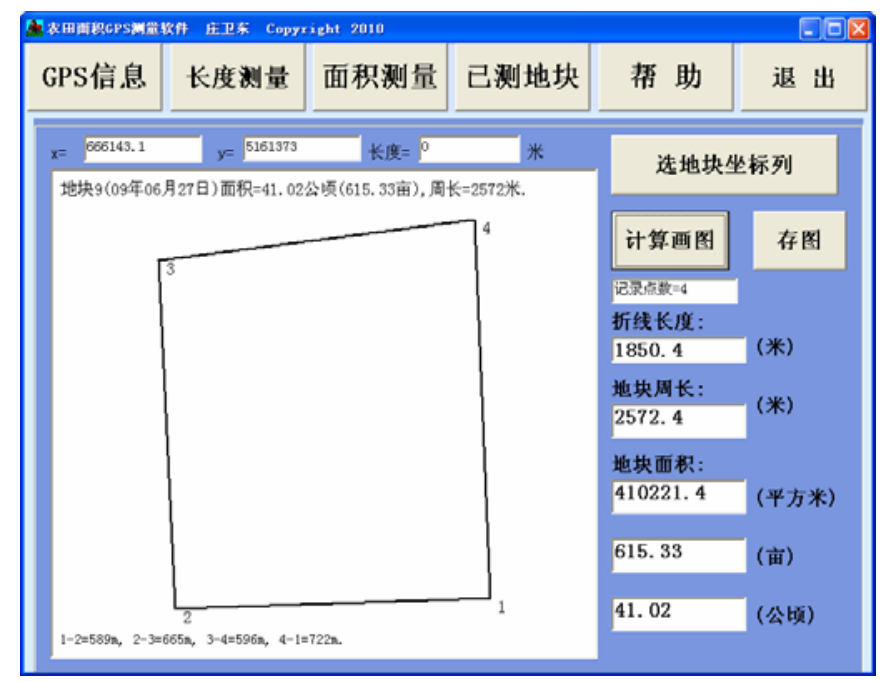

Fig. 2. Demonstration of Software

Table 1. Example of field survey data

\begin{tabular}{cllll}
\hline ID & Date & Time & Longitude & Latitude \\
\hline 1 & $09-06-27$ & $11: 02: 41$ & 125.1583 & 46.58145 \\
2 & $09-06-27$ & $11: 05: 52$ & 125.1581 & 46.58743 \\
3 & $09-06-27$ & $11: 08: 38$ & 125.1659 & 46.58799 \\
4 & $09-06-27$ & $11: 11: 39$ & 125.1660 & 46.58150 \\
\hline
\end{tabular}

the application software .system uses Visual Basic 6.0 to establish the application program and uses MSComm controls and the DGPS receiver, uses Microsoft Access 2000 database to store location data. uses ADO database connection ${ }^{[10]}$. Software should finish the function that the GPS receives processing information, farmland area, perimeter of measurement, storage data and calculated data and drawing, the block diagram storage etc. The function of software diagram is to see figure 1 . The development of software is operated as figure 2.The database for the measurement data of land is in table 1.

\section{Area Measurement Test and Application}

\subsection{Area Measurement Test}

In order to test the performance of the system in June 2009, using AgGPS 332 receiver, the touch-screen vehicle carries the computer and the MSA2 satellite signal is to test the DGPS area measurement that chooses 3 quadrilateral plot in Heilongjiang Bayi Agriculture University campus, it is tested by 3 replications respectively. Measuring results in table 2 . 
It can be shown from the table 2, area measurement using DGPS is repeated well and measurement error is very small. Furthermore, with the increase of measuring plot area, the measure of the relative errors is decreased. It can completely meet the requirement of agricultural land area.

Table 2. Measurement and analysis of DGPS area

\begin{tabular}{cllllll}
\hline & \multicolumn{2}{c}{ Location 1 } & \multicolumn{2}{c}{ Location 2 } & \multicolumn{2}{c}{ Location 3 } \\
\cline { 2 - 7 } & Circumference & Area & Circumference & $\begin{array}{l}\text { Area / } \\
\mathrm{m}^{2}\end{array}$ & $\begin{array}{l}\text { Circumference/ } \\
\mathrm{m}\end{array}$ & $\begin{array}{l}\text { Area } \\
/ \mathrm{m}^{2}\end{array}$ \\
\hline 1 & 137.3 & 1096.3 & 185.3 & 1988.6 & 2570.9 & 409723.4 \\
2 & 137.1 & 1093.2 & 185.4 & 1985.4 & 2571.8 & 410017.6 \\
3 & 137.7 & 1102.9 & 185.6 & 1991.0 & 2572.4 & 410221.4 \\
\hline Average & 137.4 & 1097.5 & 185.4 & 1988.3 & 2571.7 & 409987.5 \\
\hline $\begin{array}{l}\text { Maximal } \\
\text { relative }\end{array}$ & 0.24 & 0.50 & 0.09 & 0.15 & 0.03 & 0.06 \\
error/\% & & & & & & \\
\hline
\end{tabular}

\subsection{Area Measurement Applications}

From June 2009 to October 2009, according to the land contracting requirements of one of the agriculture company in Qiqihar, heilongjiang province, China. AgGPS332 and the software is used for the measure the farmland area which was $22817 \mathrm{hm}^{2}$. Using software and the DGPS receiver compared with traditional method of using altazimuth and meter rule that the first is measuring speed, high accuracy and the application effect is very good.

\section{Conclusion}

The Satellite different signal high-precision DGPS receiver in agricultural production is widely used in the field, Such as farmland surveying and mapping, soil sampling, fertilization, crop growth, production monitoring etc. According to the demand of agricultural production units, using DGPS receiver, touch screen, the development of the farmland information collection and processing software can improve the efficiency and quality of the farmland information acquisition, reduce costs and the difficult work.

\section{References}

1. Weidong, Z.: Research on GPS and GIS Applied in Precision Agriculture. Guangming Daily Press, Beijing (2009)

2. Yang, Q., Pang, S., Yang, C., et al.: Variable rate irrigation control system integrated with GPS and GIS. Transactions of the CSAE 22(10), 134-138 (2006) (in English with Chinese abstract)

3. Devlin, G.J., McDonnell, K.P., Ward, S.M.: Performance accuracy of low-cost dynamic non-differential GPS on articulated trucks. ASABE Journals, Applied Engineering in Agriculture 23(3), 273-279 (2007) 
4. Yang, Q., Zhang, Z.P.S., et al.: Field vehicle position monitoring system based on GPS and GIS. Transactions of the CSAE 20(4), 84-146 (2004) (in Chinese with English abstract)

5. Stoll, A., Kutzbach, H.D.: Guidance of a Forage Harvester with GPS. Precision Agriculture 2, 281-291 (2000)

6. Smith, L.A., Thomson, S.J.: GPS Position Latency Determination and ground speed calibration for the SATLOC M3. ASABE Journals, Applied Engineering in Agriculture 21(5), 769-776 (2005)

7. He, Y., Fang, H., Feng, L.: Information Processing System for Precision Agriculture Based on GPS and GIS. Transactions of the CSAE 18(1), 145-149 (2002) (in Chinese with English abstract)

8. Wang, X., Wang, X., Wang, C., et al.: Application test of soybean sowing by variable fertilization seeder in Heilongjiang reclamation areas. Transactions of the CSAE 24(5), 143-146 (2008) (in Chinese with English abstract)

9. Zhuang, W., Wang, C.: The Arithmetic of DGPS Guidance for Agriculture Machinery Straight Line Operation. Journal of Heilongjiang Bayi Agriculture University 18(6), 50-53 (2006) (in Chinese with English abstract)

10. Zhuang, W., Yang, C., Wang, C., et al.: Agriculture Machinery Operation Guidance System Based on GPS and GIS. Journal of Heilongjiang Bayi Agriculture University 20(5), 32-34 (2008) (in Chinese with English abstract) 